
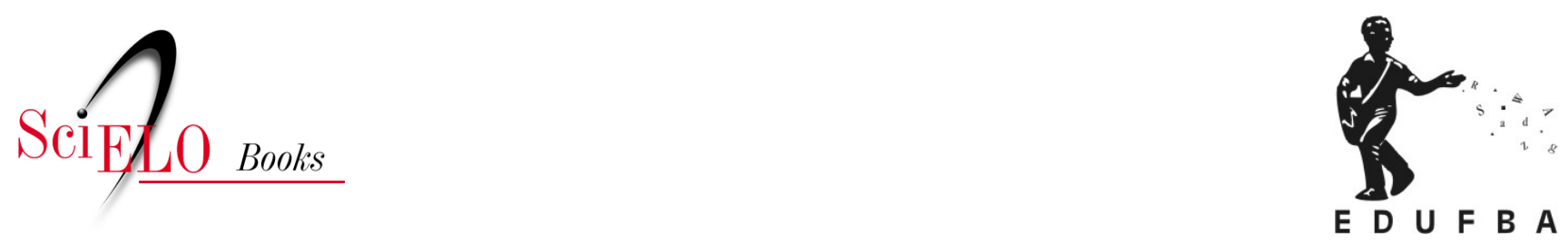

\title{
Capoeira regional
}

do abadá à beca

\section{Hellio Campos}

\section{SciELO Books / SciELO Livros / SciELO Libros}

CAMPOS, H. Capoeira regional: do abadá à beca. In: Capoeira regional: a escola de Mestre Bimba [online]. Salvador: EDUFBA, pp. 96-118. ISBN 978-85-232-1727-3. Available from: doi: 10.7476/9788523217273.0011. Also available in ePUB from:

http://books.scielo.org/id/p65hq/epub/campos-9788523217273.epub.

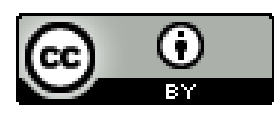

All the contents of this work, except where otherwise noted, is licensed under a Creative Commons Attribution $\underline{4.0 \text { International license. }}$

Todo o conteúdo deste trabalho, exceto quando houver ressalva, é publicado sob a licença Creative Commons Atribição 4.0. 


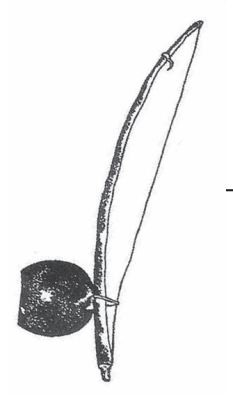

Capoeira regional: do abadá à beca

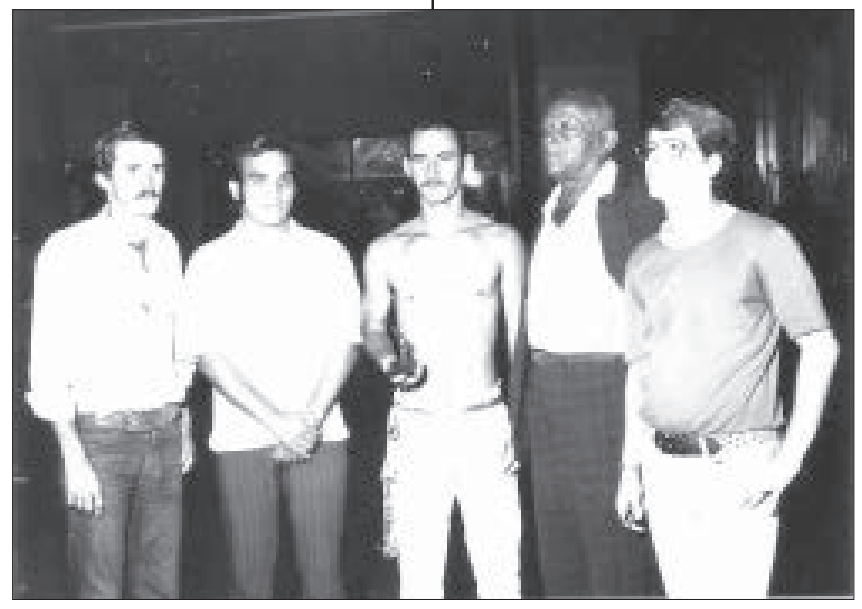


Como uma manifestação afro-brasileira, a capoeira tem se mostrado ao longo da sua trajetória um fenômeno de resistência singular. Conseguiu sair de situações demasiadamente desfavoráveis, a exemplo da marginalização e do Código Penal Brasileiro, resistiu aos Capitães do Mato, à perseguição policial e, principalmente, à mais perversa das perseguições: a injúria social.

A capoeira não se deixa abater por esses desagravos sociais e imensos obstáculos; resiste, recriando no cotidiano das rodas a sua história, exprimindo, sobretudo nas letras das músicas, seus sentimentos, suas dores, suas verdades e suas paixões, que são oralmente valorizadas, passando dos mais velhos para os mais jovens, no seio familiar ou mesmo no âmbito da comunidade, e realçando, dessa forma, a história oral como fonte inesgotável de transmissão dos conhecimentos e de tradições.

Resistindo a todas as pressões, a capoeira, no percurso de sua existência, vem conquistando espaços no mundo em que está inserida; e Mestre Bimba, um capoeirista nato, um autêntico representante do que poderíamos chamar do ciclo heróico dos negros da Bahia, teve como ideal "tirar a Capoeira de baixo do pé do boi" e mostrar o seu valor para quem quer que seja e em qualquer lugar, dos mais simples aos mais "nobres".

\section{CAPOEIRA REGIONAL: EXPERIÊNCIAS UNIVERSITÁRIAS}

As evidências nos levam a crer que a Capoeira Regional adentra o meio acadêmico, por iniciativa dos alunos de Mestre Bimba, sendo que o principal argumento sugere precipuamente a aproximação física entre a Faculdade de Medicina da Bahia, situada no Terreiro de Jesus, e a academia de Mestre Bimba, distante aproximadamente trezentos metros, localizada na rua do antigo Maciel de Cima, uma via de acesso ao Terreiro de Jesus, conhecida também como Centro de Cultura Física Regional, bem como a relação estreita entre seus alunos e a consequente incorporação de elementos acadêmicos à própria Capoeira Regional.

Outro aspecto relevante diz respeito diretamente a um estudante de medicina chamado Cisnando Lima que, apaixonado pelas artes marciais, logo que chegou a Salvador, percorreu as rodas de capoeira procurando um mestre para the ensinar a dança guerreira dos negros da Bahia. 
De acordo com Decanio - colega e amigo de Cisnando -, o mesmo descobriu Mestre Bimba "numa roda de capoeira no Curuzú, a quem logo escolheu para 'mestre', impressionado pelas habilidades exibidas e pela técnica nitidamente superior à de todos os que tinha presenciado". Decidido, submeteu-se aos testes de admissão aplicados por Bimba, demonstrando coragem e resistência, consideradas como a "única porta de entrada para a roda de Mestre Bimba" (1996, p. 111).

Cisnando foi o primeiro aluno branco pertencente a uma classe social abastada de Salvador a praticar a capoeira e também foi o principal interlocutor entre Mestre Bimba, a Capoeira Regional e a universidade.

Idealista, sonhador e com a impetuosidade de um jovem acadêmico, induziu Mestre Bimba a enriquecer a "Luta Regional Baiana", a registrá-la, a introduzi-la na estrutura social da época, a adquirir o direito à liberdade de ensino, a fugir da marginalidade e a ganhar ares de cidadania, através da prática regulamentada.

Outro feito de Cisnando - e a verdadeira razão do seu empenho - foi o de divulgar a Capoeira Regional entre os seus colegas, companheiros de geração, e estreitar as relações entre a capoeira - uma prática marginalizada, discriminada - e a universidade, uma instituição que abriga a elite do povo brasileiro por ser considerada uma casa privilegiada dos saberes.

Apesar da capoeira ser considerada uma atividade à margem da sociedade, constatamos a sua presença, de alguma maneira, dentro das instituições de ensino - especialmente a universitária - consubstanciada pela sua prática espontânea e informal. Sabemos também, pelos informes de ex-alunos de Mestre Bimba, em especial daqueles que frequentaram a faculdade de medicina, que os mesmos incentivaram a prática da capoeira dentro dos muros da universidade, no sentido de mostrar aos seus colegas a sua arte de capoeirar.

Esses estudantes universitários, não apenas praticavam a capoeira, como organizavam grupos folclóricos com o intuito de se apresentarem nos mais variados eventos acadêmicos. Senna conta que "a capoeira tornou-se espetáculo folclórico através dos estudantes universitários baianos que praticavam a regional” (1990, p. 39). Afirma que a principal motivação era a de se apresentar em shows, com o objetivo de angariar fundos para as suas viagens acadêmicas, congressos, seminários e jogos universitários.

A capoeira foi ganhando, aos poucos, notoriedade, a ponto da sua recepção no meio acadêmico gozar de simpatia, em face do expressivo valor educativo e cultural. Por outro lado, existiu a preocupação dos mestres de capoeira para que a mesma não se engessasse academicamente, perdendo, assim, a sua autenticidade.

Edivaldo Boaventura, em matéria publicada no jornal A Tarde, em janeiro de 1988, "A baianização do currículo", defende, sobremaneira, a aproximação curricular com a cultura, afirmando ser sempre uma preocupação dominante nos educadores. Diz mais: "a educação, para que seja realmente nacional, há de refletir valores, condicionamentos e ingredientes 
culturais". Nesta matéria, destaca a importância da língua pátria e da introdução dos estudos africanos.

Em 16 de setembro de 1999, Edivaldo Boaventura volta à tona com a questão da capoeira e a universidade e, desta vez, em seu artigo "A capoeira de beca", destaca suas múltiplas representações: capoeira como dança, arte, folclore, luta, esporte, lazer e filosofia de vida. Lembra ainda que "se a cultura é o fundamento do currículo, a Capoeira Regional centra-se no eixo do ensino da nossa educação física, como autêntica matéria, ministrada academicamente como disciplina e como atividade, com plena aceitação dos alunos".

Revela que a capoeira foi criada pelo povo e que, caso seja sistematizada e trabalhada academicamente, será capaz de se integrar perfeitamente à universidade, formando, ao lado dos clássicos métodos da educação e da educação física, uma temática singular de estudo.

Em outra matéria publicada também no jornal A Tarde, no dia 28 de setembro de 2000, ressalta a recepção e as boas-vindas da universidade à capoeira, considerando o seu valor educacional e cultural. Dá ênfase à "aproximação pedagógica e antropológica da capoeira, como disciplina acadêmica" e incentiva o apoio acadêmico.

Percebe-se que a Capoeira está inserida e devidamente integrada nas universidades brasileiras. Está presente das mais variadas formas, primeiramente de maneira totalmente informal, para depois ser consubstanciada dentro dos currículos, especialmente nos cursos de Educação Física como uma disciplina desportiva, detentora de forte apelo social e cultural.

As primeiras manifestações a favor da capoeira no currículo dos cursos universitários aconteceram na Bahia. Inicialmente, inserida no programa curricular do Programa de Melhoria de Ensino Nacional (PREMEM), do Ministério da Educação e Cultura, desenvolvido pela Faculdade de Educação da Universidade Federal da Bahia em 1971.

O PREMEM foi um programa emergencial criado para atender às demandas do ensino de primeiro grau das escolas polivalentes. A capoeira integrou as atividades da disciplina educação física, atendendo a um total de 657 alunos, divididos em grupos por faixa etária. O objetivo da disciplina era o de favorecer uma sociabilidade que permitisse suavizar a carga de estudo a que se encontravam submetidos os estudantes. O caráter relaxante e descontraído foi um marco da disciplina.

As atividades propostas foram a Ginástica, Voleibol, Futebol de Salão, Basquetebol, Handebol, Atletismo e Natação. A capoeira entrou no contexto pela via da Ginástica sendo ministrada por Mestre Xaréu e Mestre Itapoan. O programa constou basicamente sobre a Capoeira Regional fundamentada nos ensinamentos e metodologia aplicada por Mestre Bimba no Centro de Cultura Física Regional. As aulas foram ministradas nas dependências da Vila Olímpica da Bahia até dezembro de 1973.

A segunda manifestação favorável à capoeira foi a do Curso Superior de Educação Física, da Universidade Católica de Salvador, quando da reforma curricular em 1982, introduzindo definitivamente a capoeira como disciplina obrigatória, com uma carga horária de $60 \mathrm{~h}$, sendo convidado para assumir a cadeira o Professor Josevaldo Lima de Jesus (Mestre Sacy), formado pela Academia de Mestre Bimba. 
Nesse período já se discutia de maneira tímida a possibilidade da inserção da capoeira como disciplina curricular, desejo especialmente dos alunos de Mestre Bimba, que tinham se aventurado a ensinar capoeira em outros estados brasileiros.

Vale registrar a presença dos alunos de Mestre Bimba nas universidades baianas, sempre engajados nos diretórios acadêmicos, associações atléticas e na Federação Universitária de Esportes. Como líderes, fomentavam a prática da capoeira em todos os segmentos, ora ministrando aulas avulsas, ora organizando grupos folclóricos, ora levando para dentro das universidades apresentações e ora discutindo-a em várias esferas.

No Estado do Rio de Janeiro, encontramos ótimas experiências com a capoeira inserida em várias faculdades e universidades, remontando à década de 1970, o que representa um pioneirismo nesse tipo de atividade.

Coube ao Grupo Senzala, em 1972, desenvolver os primeiros trabalhos desse gênero, quando o grupo teve acesso ao curso de engenharia da antiga Universidade do Estado da Guanabara (UEG), atualmente a Universidade do Estado do Rio de Janeiro (UERJ). Nesse ano, relata o Prof. Augusto José Fascio Lopes ${ }^{1}$ (Mestre Anzol), alunas do curso de direito reivindicaram o direito de praticarem a capoeira dentro do programa da prática desportiva obrigatória e que, a princípio, houve desconfiança do reitor, até certa resistência, pois o mesmo tinha dúvidas de que as alunas pudessem participar, sem comprometimento físico e psicológico, das aulas de capoeira. Sendo as dúvidas devidamente esclarecidas, o curso transcorreu sem maiores problemas.

O Estado do Rio de Janeiro sempre se pautou por ser um pólo importante de capoeira. Soares, reportando-se ao século XIX, evidencia a chegada da Família Real ao Brasil, em 1808, e a Abdicação do primeiro imperador, em 1831, lembrando que a capoeira era o "flagelo" das autoridades competentes em manter a ordem no Império. Distingue a época que chamou de crítica durante a formação do Estado nacional, já que "como expressão combativa da massa escrava negro-africana, que monopolizava o trabalho na cidade, a capoeira foi canal expressivo da resistência escrava, e por isso vítima permanente da violência senhorial e policial" (1994, p. 7). Cita Adolfo Morales de Los Rios Filho - cuja obra trata do Rio de Janeiro à época imperial - que apresenta significativas e meritórias observações sobre a origem dos capoeiristas, chamando a atenção pela primeira vez das consequências da escravidão urbana como o provável berço da capoeira. Os escravos urbanos adeptos da capoeiragem trabalhavam essencialmente como pretos de ganho, carregadores de toda ordem, serviçais, vendedores, mariscadores, peixeiros e pescadores.

A capoeira do Rio de Janeiro se expressa pelas maltas de capoeira, o que Soares intitula de "unidade fundamental da atuação dos praticantes de capoeiragem". Tais unidades ou grupos eram formados por até cem indivíduos, sendo a "malta uma forma associativa de resistência mais comum entre escravos e homens livres pobres no Rio de Janeiro da segunda metade do século XIX”. 
Esses grupos aos poucos foram se organizando, a ponto de se constituírem em duas "nações": a dos "guaiamus"' e a dos "nagôs", que mantinham uma rivalidade severa, permanecendo quase todo tempo em guerra entre si.

Soares, narrando a violência nas festas populares e religiosas na cidade e outros encontros, em função de novas tradições criadas pelo Estado Imperial, ressalta que "eram oportunidades que as maltas não perdiam de exibir suas habilidades públicas, ou resolver contendas que, não raro, degeneravam em tumultuados conflitos que o poder policial raramente conseguia coibir" (1994, p. 72).

Historicamente, a capoeiragem do Rio de Janeiro torna-se singular não apenas pelas maltas — os Nagôas e os Guaiamus — mas, também, pelos famosos capoeiristas de outrora e pela capoeira diferenciada do presente.

Assim, o Rio de Janeiro tem se constituído como uma referência na arte de capoeirar, principalmente pelos numerosos grupos de capoeira, pelos campeonatos universitários, pelos megaeventos e pela inserção da capoeira em muitos projetos universitários. Podemos citar algumas experiências nas universidades Estácio de Sá, Gama Filho, Castelo Branco, Bennett, UERJ, Federal Rural e Federal do Rio de Janeiro, as quais contemplam a capoeira nos seus currículos e através de projetos de prática desportiva, extensão e pesquisa.

Outro aspecto importante é que aos poucos a educação física foi se apropriando da capoeira como uma disciplina interessante para complementar o currículo de formação profissional. A justificativa recai, principalmente, sobre o valor educacional e cultural da capoeira, ou seja, um esporte autenticamente brasileiro que pode ser contemplado de várias maneiras. César Augustus Barbieri, em sua tese de doutorado "O que a escola faz com o que o povo cria: até a capoeira entrou na dança!", defendida na Universidade de São Carlos, em 2003, observa que:

Em todos os períodos, tradicionalmente estabelecidos pelos estudiosos da história desse processo de construção de nossa formação social, encontramos, de uma forma ou de outra, direta ou indiretamente, registros de interpretação que indicam a rica e complexa polissemia que caracteriza as diversas interpretações sobre "o que é" a Capoeira.

Barbieri aprofunda mais a questão na tentativa de entender o fenômeno capoeira, recorrendo a Heidegger, baseado no conceito de dasein, entendido pelo processo ser-no-mundo. Ele se refere aos vários sentidos atribuídos à capoeira em épocas diferentes, os quais vão se modificando ao "longo dos anos (ou melhor, dos séculos), perdendo sua força e ficando quase que esquecidos; outros revigorando-se e quase sobrepujando os demais, tornandose uma referência; e, ainda, outros tantos novos sentidos surgindo, a cada dia que passa, como é possível ao abordar-se as diversas interpretações desse fenômeno".

Continuando em sua busca para compreender o fenômeno capoeira, agora pela visão dialético-fenomenológica da relação homem-mundo-fenômeno, Barbieri também mira a concepção materialista-dialética da realidade e diz fazer-se "necessário que sejam considerados os diversos sentidos atribuídos à capoeira, tais como luta, dança, arma, brinquedo, 
defesa pessoal, atividade criminosa, arte, jogo, esporte, arte marcial, terapia, educação física e movimento político social".

Outras universidades brasileiras têm despontado com trabalhos singulares sobre a capoeira, contemplando sua prática em formas diferenciadas de entendimento, mas valorizando principalmente os aspectos histórico, esportivo, social, educacional e cultural.

Na atualidade, a capoeira tem se consolidado nos cursos de educação física de todo o território brasileiro. No meu entendimento, o que favoreceu sobremaneira essa inserção nos currículos, além do reconhecimento do seu valor educacional e cultural, do esforço pessoal de mestres de capoeira e professores de educação física, foi a abertura singular conferida pela Resolução n ${ }^{\circ} 3$, de 16/6/1987, do Conselho Federal de Educação, que trata da formação dos profissionais de educação física, bacharéis ou licenciados. Em seu Art. $3^{\circ}$, relativo ao Conhecimento Técnico, o inciso $2^{\circ}$ estabelece:

Que cada Instituição de Ensino Superior (IES) partindo dessas outras áreas elaborará o elenco de disciplinas da parte da formação geral do currículo pleno, considerando as peculiaridades de cada região e os perfis profissionais desejados (Bacharelado e/ou Licenciatura Plena).

A abertura estabelecida pela Resolução 03 veio em boa hora, justamente quando a educação física passava por uma "crise" de identidade, cuja discussão iniciou-se de forma mais veemente durante o "II $\mathrm{I}^{\circ}$ Congresso Brasileiro de Esporte para Todos", em 1984. Nessa oportunidade, foi elaborada a "Carta de Belo Horizonte", enfocando a necessidade de reformulação curricular visando à concepção de um novo profissional de educação física que pudesse atender aos anseios da população brasileira.

Depois de publicada a Resolução 03/87, todos os cursos de educação física tiveram um período para adequação dos seus currículos, o que facilitou, no nosso entender, a inclusão da disciplina capoeira, ora como disciplina de caráter obrigatório, ora como disciplina opcional de aprofundamento, ora como disciplina eletiva.

A inserção da capoeira nas faculdades e universidades nem sempre ocorreu de forma amistosa; em muitas ocasiões, os professores que defendiam a inclusão da capoeira no currículo tiveram verdadeiros embates com seus pares, no sentido de justificar e mostrar a relevância da capoeira como disciplina para a formação do profissional de educação física. $\mathrm{E}$ nesse esforço aconteceram fatos curiosos, que relatamos em seguida.

No IPA ${ }^{4}$, a capoeira foi introduzida de maneira inusitada, até mesmo como desafio, conta o Prof. Carson Siega ${ }^{5}$, atual professor da disciplina capoeira.

Carson conta que, quando aluno do curso de educação física do IPA, em 1981, participava no intervalo das aulas de rodas de capoeira organizadas pelos alunos que já tinham uma vivência do jogo quando:

Certa vez, durante uma roda, no intervalo das aulas, onde todos se divertiam com uma capoeira em "alto astral", chegou um funcionário do IPA, a mando do reitor, ordenando que a roda terminasse, pois essa atividade havia sido proibida dentro da instituição. 
Intrigado com o acontecido, Carson procurou desvendar o mistério da proibição e chegou à informação de que a capoeira era proibida na instituição por ser a mesma praticada por "desordeiros", "politiqueiros de esquerda" e até "drogados".

Por meio de um trabalho voluntário começou, juntamente com um colega, a ministrar aulas de capoeira na $\mathrm{ESEF}^{6}$, sendo em seguida convidado pelo reitor para fundar um grupo de capoeira, com a finalidade de atender aos alunos de $1^{\circ}, 2^{\circ}$, e $3^{\circ}$ graus da instituição. $\mathrm{O}$ grupo funcionava em caráter de programa de extensão universitária, trabalho que rendeu bons frutos, pois a capoeira passou a ser vista como uma atividade de importância vital na educação dos jovens gaúchos.

Com a reforma curricular, a disciplina capoeira foi devidamente contemplada, sendo feito, posteriormente, um concurso para a cadeira, no qual o Prof. Carson Siega teve a oportunidade de lograr aprovação, estando atualmente ministrando a disciplina no sétimo semestre, com um programa bem peculiar, envolvendo os fundamentos da capoeira.

Em recente conversa com o Prof. Carson Siega, soube que numa adequação curricular a disciplina capoeira foi transformada em uma disciplina de lutas, porém o conteúdo da capoeira continua no bojo do programa.

$\mathrm{Na} \mathrm{USP}^{7}$, a capoeira está presente principalmente no $\mathrm{CPUSP}^{8}$, como disciplina obrigatória para atender à prática desportiva e aos cursos de extensão dirigidos, especialmente, à comunidade infanto-juvenil. Também está inserida como disciplina de caráter obrigatório na grade curricular do curso de Educação Física. Outro projeto atende às faculdades de Farmácia, Química, Arquitetura, Politécnica, Psicologia, Educação Física, sindicatos dos funcionários, Conjunto de Moradores da CPUSP e Instituto de Pesquisas Tecnológicas, através de professores de capoeira devidamente contratados pelos centros acadêmicos.

Importante registrar a presença da capoeira em outros campi e faculdades: campi de Bauru, São Carlos, Ribeirão Preto e Pirassununga. Nas faculdades de San Remo, Engenharia Mauá, Anhembi e, ainda, nas universidades Mackenzie, São Judas Tadeu, Unicamp, UNESP (de Rio Claro), Unicastelo, Mogi das Cruzes e Santo André.

A rigor, encontramos professores de educação física e capoeiristas atuando junto às comunidades universitárias de modo geral.

O processo de aproximação da capoeira das universidades paulistas foi acontecendo gradativamente pela oportunidade que as academias de capoeira tiveram de participar de eventos diversos, a convite dos alunos universitários ou mesmo dos diretores dos centros acadêmicos.

Na atualidade, é difícil enumerar e possivelmente listar todos os cursos de educação física que contemplam a disciplina capoeira, contudo vale registrar que existem trabalhos bem expressivos.

No Estado da Bahia - considerado o berço da capoeiragem - praticamente todos os cursos de educação física conferem à disciplina tratamento especial, incluindo-a no currículo em caráter obrigatório. Essa deferência deve-se à valorização de uma manifestação afro-descendente, amparada pelo substrato cultural e popular, e bem aceita pelos estudantes. 
Na Escola de Educação Física da Universidade Católica do Salvador, a disciplina Capoeira Desportiva é de caráter obrigatório, sendo ministrada no sexto semestre com um enfoque mais desportivo, como disse o Prof. Josevaldo Lima de Jesus (Mestre Sacy) ${ }^{9}$, que afirma: "trato ela não apenas como capoeira luta, capoeira folclore somente, mas também como atividade de competição, um desporto, com suas regras, com as suas vantagens e apreciação das qualidades físicas". Ele cita que teve dificuldades na ocasião da implementação da disciplina por ser a primeira experiência brasileira e, portanto, não tinha referências para a elaboração do programa do curso e, por isso, baseou-se na metodologia adotada por Bimba para o ensino da Capoeira Regional; revela, ainda, que contou com a decisiva ajuda do professor Evilásio Rodrigues.

Na atualidade, a disciplina EDF 383 - Capoeira Desportiva - tem uma carga horária de 60 horas, 3 créditos e não tem pré-requisitos, sendo desenvolvida com seguinte ementa:

Origem e desenvolvimento da capoeira, aspectos filosóficos, antropológicos e educacionais desportivos, música e instrumentos, sequências, jogos, elaboração de eventos (formativos e lúdicos), aspectos técnicos e táticos, métodos de treinamento e regulamento técnico (competições e arbitragens).

O Curso de Licenciatura em Educação Física da Universidade Federal da Bahia, que está lotado na Faculdade de Educação, valoriza bem a capoeira sob vários aspectos: (a) como disciplina inserida no currículo em dois momentos, o primeiro como disciplina obrigatória e o segundo como disciplina optativa; (b) através da Atividade Curricular em Comunidade (ACC) e também em eventos diversos (seminários, debates, grupos de estudo, apresentações etc.).

Já a disciplina EDC 238 - Capoeira I - conta com carga horária de 60 horas e se baseia em uma ementa que enaltece o estudo de abordagens históricas e conceituais da capoeira como um todo:

Estudo de abordagens históricas e conceituais sobre Capoeira. A herança das danças, lutas e jogos como construção de identidade étnica e cultural africano-brasileira. Aspectos históricos, filosóficos, técnicos e sócio-culturais da Capoeira Angola. Fundamentos básicos da Capoeira Angola. Processos de reelaboração da Capoeira na Bahia. A Capoeira Regional, suas referências históricas, filosóficas e técnicas. Estudo biográfico dos principais representantes da Capoeira na Bahia.

A disciplina EDC 239 - Capoeira II — tem uma carga horária maior, ou seja, de 75 horas, justificada por ser uma disciplina optativa e de aprofundamento. Sua ementa sugere um enfoque mais reflexivo e investigativo sobre a problemática da capoeira:

Estudo da problemática da Capoeira no contexto baiano e brasileiro. Crise identitária e o surgimento de segmentos e diferentes escolas com seus processos metodológicos de ensino. Desenvolvimento dos fundamentos da Capoeira. Produção de conhecimentos refletindo sobre questões atuais que envolvem a Capoeira e suas dimensões, considerando necessidades e interesses do aluno e da turma.

Por outro lado, o Programa de Pós-graduação em Educação também confere seu valor à capoeira, ao autorizar, em 2000, o funcionamento da disciplina Educação, Cultura e Capoeira, ministrada como Tópico Especial em Educação, o que constituiu uma iniciativa inédita e bem-sucedida, marcando sobremodo a inclusão da capoeira como tema a ser 
discutido academicamente. Além do mais, tem aumentado significativamente o número de candidatos inscritos nos cursos de mestrado e doutorado que apresentam projetos sobre a temática da capoeira, indicando, assim, um interesse singular.

Podemos destacar, ainda, na UFBA, outras iniciativas, a exemplo das escolas de Dança e de Teatro e da Faculdade de Ciências Humanas, que têm incentivado muitos projetos de extensão e pesquisa nessa área.

A rigor, a UFBA tem despontado como uma universidade que reconhece o valor educativo e cultural das manifestações culturais e populares do povo baiano, principalmente admitindo a importância da interação da academia junto às manifestações advindas historicamente do povo.

A outorga do título de Doutor Honoris Causa (post-mortem) a Manoel dos Reis Machado (Mestre Bimba) torna patente a atenção que a UFBA tem destinado a projetos dessa natureza. Recentemente, foi aprovado pelo Departamento de Educação Física, da Faculdade de Educação, um projeto para conferir, também, o título de Doutor Honoris Causa a João Pereira dos Santos (Mestre João Pequeno).

Muitas são as universidades brasileiras que tratam do fenômeno capoeira como um objeto de estudo importante. Na sua maioria, iniciando seus estudos nos cursos de graduação em educação física para, daí, criarem uma motivação particular com a finalidade de aprofundamento dos conhecimentos através dos projetos de pesquisa e extensão.

Encontramos referências nas seguintes instituições de ensino superior: Universidade Federal de Minas Gerais, Universidade Estadual de Maringá, Universidade Federal de Santa Catarina, Universidade Federal de Brasília, Universidade Estadual de Campinas, Universidade Gama Filho, Universidade Federal de Sergipe, Universidade de Santa Cruz do Sul, Universidade Federal de Pernambuco, Universidade Rural de Pernambuco, Universidade Estadual de Feira de Santana, Universidade Estadual do Sudoeste da Bahia, Universidade Federal do Rio de Janeiro, Universidade Federal do Piauí e tantas outras.

A "Revista Capoeira: Arte e Luta Brasileira", Ano II, no 10 traz, nesta edição, a cobertura completa do $\mathrm{I}^{\circ}$ Festival Ford Universitário de Capoeira, evento que foi uma realização da própria revista. O festival aconteceu em São Bernardo do Campo (SP), em 2000, contando com a participação de dezoito faculdades e universidades.

A matéria mostra o interesse dos universitários por esse tipo de evento, que congregou 250 atletas disputando as seguintes modalidades: individual (masculino e feminino) e por equipe. A platéia foi de aproximadamente três mil animados espectadores e o evento teve a parceria da Federação Universitária Paulista de Esportes (FUPE) e o patrocínio da Ford do Brasil. Ainda contou com o decisivo apoio do Governo do Estado de São Paulo, Secretaria de Esportes e Turismo da Prefeitura e importantes empresas privadas.

Sobre o acontecimento, Luiz Renato Vieira, professor da Universidade de Brasília e mestre de capoeira, assim declarou: 
Eventos dessa natureza, nesse padrão de organização, seriedade e ao mesmo tempo amizade e descontração, são excelentes para a capoeira, pois a colocam no patamar merecido sem "burocratizar". Ao contrário, aproximam as pessoas, constroem amizades e elevam a nossa luta.

Nas nossas observações não temos visto muitos encontros destinados ao público universitário brasileiro, o que exprime uma carência no fomento à prática esportiva nas instituições do ensino superior brasileiro.

Outras iniciativas que valem registro neste trabalho referem-se aos cursos de pós-graduação na área específica da capoeira. A primeira ação incomum nesta direção foi organizada pela Universidade de Brasília (UnB), através do "Curso de Especialização em Capoeira na Escola" (lato sensu), com carga horária de 375 horas. Realizado no período de $1^{\circ}$ de setembro de 1997 a 30 de junho de 1998, contou com a seguinte grade de disciplinas:

Tabela 1 - Grade Curricular do Curso de Especialização em Capoeira na Escola, da UnB

\begin{tabular}{|l|l|l|}
\hline História da Capoeira & Capoeira na Escola & $\begin{array}{l}\text { Fundamentos Pedagógicos } \\
\text { da Educação Física Escolar }\end{array}$ \\
\hline $\begin{array}{l}\text { Metodologia Aplicada à } \\
\text { Capoeira I }\end{array}$ & Didática do Ensino Superior & $\begin{array}{l}\text { Fundamentos Sócio- } \\
\text { filosóficos da Capoeira }\end{array}$ \\
\hline $\begin{array}{l}\text { Cultura e Tradição/Rituais } \\
\text { da Capoeira }\end{array}$ & $\begin{array}{l}\text { Expressão Corporal em } \\
\text { Capoeira }\end{array}$ & $\begin{array}{l}\text { Organização e Normatização } \\
\text { da Capoeira }\end{array}$ \\
\hline Metodologia da Pesquisa & $\begin{array}{l}\text { Metodologia Aplicada à } \\
\text { Capoeira II }\end{array}$ & $\begin{array}{l}\text { Fundamentos Técnicos da } \\
\text { Capoeira }\end{array}$ \\
\hline $\begin{array}{l}\text { Processos de Ensino- } \\
\text { aprendizagem de } \\
\text { Habilidades Motoras na } \\
\text { Capoeira }\end{array}$ & $\begin{array}{l}\text { Fundamentos Musicais e } \\
\text { Instrumentação da Capoeira }\end{array}$ & $\begin{array}{l}\text { Bases Morfo-fisiológicas da } \\
\text { Prática da Capoeira }\end{array}$ \\
\hline $\begin{array}{l}\text { Seminário de } \\
\text { Monografia/Projeto }\end{array}$ & $\begin{array}{l}\text { Elaboração de } \\
\text { Monografia/Projeto }\end{array}$ & \multicolumn{2}{|l}{} \\
\hline
\end{tabular}

O segundo, foi o curso sequencial "Curso de Nível Superior em Capoeira", idealizado pela Universidade Gama Filho (UGF), com uma carga horária total de 460 horas e um sugestivo elenco de disciplinas expresso na tabela a seguir:

Tabela 2 Grade Curricular do Curso de Nível Superior em Capoeira da UGF

\begin{tabular}{|l|l|l|}
\hline Antropologia da Capoeira & Didática & Organização de Eventos \\
\hline Anatomia & Estágio I, II, III, IV & Preparação Física Aplicada \\
\hline Biomecânica Aplicada & Fabricação de Instrumentos & Psicologia Aplicada \\
\hline Capoeira p/Especial & Fisiologia I e II & Recreação na Capoeira \\
\hline Cultura Afro-Brasileira & Historia da Capoeira I e II & Ritmos e Cantigas \\
\hline $\begin{array}{l}\text { Desenvolvimento de } \\
\text { Aprendizagem I e II }\end{array}$ & Medicina Aplicada & $\begin{array}{l}\text { Treinamento Desportivo I e } \\
\text { II }\end{array}$ \\
\cline { 1 - 2 } Administração e Marketing & Metodologia da Capoeira & \multicolumn{2}{|l}{} \\
\cline { 1 - 2 } & \multicolumn{2}{|l|}{} \\
\cline { 1 - 2 } & &
\end{tabular}

Nos nossos estudos, principalmente durante a pesquisa da nossa tese de Livre Docência: "Capoeira, do popular para a universidade: uma trajetória de resistência", defendida na American World University (AWU), em 1999, encontramos importantes declarações dos sujeitos investigados sobre o assunto em discussão. 


\section{ASPECTOS DA CONQUISTA E RESISTÊNCIA}

Buscando compreender os aspectos relativos à conquista e à resistência da capoeira, bem como identificar os fatores que levaram à sua inserção em contexto universitário, colocamos a seguinte questão aos nossos entrevistados: em sua opinião, de que maneira a capoeira conquistou a universidade? E quais os motivos que levaram a essa conquista?

Ao examinar as respostas deste questionamento, encontramos dois pontos de vista divergentes: o primeiro, com um percentual de $86 \%$, afirma que a capoeira já conquistou a universidade e o segundo, com apenas $14 \%$, assevera que a capoeira ainda não a conquistou.

Um dos entrevistados diz que a aproximação da capoeira com a universidade deve-se "ao processo de democratização do sistema universitário", "à abertura da universidade para a cultura popular" e "ao reconhecimento de artistas e intelectuais da capoeira como uma prática valiosa de cunho educacional e cultural". Outro afirma que "a capoeira ainda está conquistando o espaço universitário" e a principal razão para isso, o que este entrevistado chama de "fenômeno", é o potencial que a capoeira possui, enquanto área de conhecimento da cultura afro-brasileira, respaldada pela dinâmica trajetória de conquistas de diferentes espaços socioculturais no Brasil. Enumera, ainda, um segundo ponto que diz ser determinante, ou seja, "a busca pedagógica de temas e conteúdos provenientes das realidades e contextos socioculturais brasileiros, discutidos nos atuais parâmetros curriculares".

Muitos dos entrevistados asseguraram que a inclusão da capoeira no contexto escolar foi um dos grandes trunfos que a levaram para dentro das universidades. Lembraram, ainda, da influência decisiva da Capoeira Regional nesse processo.

A presença da capoeira nas instituições de ensino formal, seja no fundamental e médio ou no meio universitário, desperta curiosidade e até mesmo espanto, especialmente por ter sido uma atividade outrora marginalizada, reprimida pela força policial e repleta de preconceitos da sociedade, que rapidamente passa a ser valorizada como uma atividade importante no contexto educacional, cultural e de formação de cidadãos.

A capoeira representa a resistência de uma arte, de um povo que, mesmo marginalizado, não se dobra frente às dificuldades, pelo contrário, encontra forças para lutar e conquistar seus merecidos espaços.

Nas rodas de capoeira uma questão sempre se faz presente: quais os tipos de resistência que a capoeira sofreu para conquistar o meio acadêmico, sabendo que a universidade é uma instituição da elite do saber e muito conservadora?

Os estudiosos, em sua maioria, são unânimes em atestar que a capoeira sofreu uma forte resistência durante toda a sua trajetória, advinda do processo brasileiro de escravidão e, sustentada pelo racismo e pelo preconceito, é entendida como uma atividade de negros, malandros, vadios, marginais e desocupados.

Reportando-se ao preconceito, e ampliando o foco até às artes e à cultura negra, observam que este é extensivo às atividades populares de um modo geral que, por vezes, são entendidas, de modo pejorativo, como coisa "de gente do povo". Nessas circunstâncias, a 
capoeira, o samba e o candomblé são usados pelos "tradicionais" como uma manifestação folclórica, o que os classifica de forma esdrúxula, oportunista e descartável.

Segundo Patrocínio, "[...] essa cultura foi caracteristicamente violentada, negada, oprimida e desfigurada ao longo dos anos pelo mercantilismo escravista, pelo racismo e pela política e ideologia do embranquecimento" (1989, p. 43).

Nossa investigação mostrou que a capoeira sofreu e sofre resistência, principalmente do sistema político-ideológico e econômico-social que discrimina referências educacionais e culturais. Revelou, ainda, que a capoeira vem resistindo para impor-se no meio social através do fazer e viver diferenciado, buscando valorizar sua própria identidade e potencialidade.

Tudo indica que a capoeira tenha se defrontado - e ainda se defronta diuturnamente - com significativas barreiras dentro da academia, principalmente o descaso científico, o elitismo intelectual e o preconceito racial e social. Alguns mestres, que tiveram de lutar para que seus projetos fossem aprovados em seus departamentos, afirmam que não encontraram uma resistência declarada à capoeira, todavia ficou subtendida uma resistência natural da sociedade brasileira, incorporada ao subconsciente através da herança cultural hegemônica.

Por outro lado, encontramos outros mestres que afirmam não terem tido dificuldades em aprovar seus projetos, pois têm encontrado apoio de toda ordem dentro dos setores acadêmicos e administrativos da universidade. Relatam, entretanto, as dificuldades encontradas em setores muito específicos, o que revela a resistência natural da sociedade brasileira em relação à herança cultural e social da raça africana.

A conceituação da capoeira no ensino formal universitário também não tem unanimidade entre os mestres e professores de capoeira. De um modo geral, alguns apontam para a evidência, que consideram verdadeiramente proveitosa para a capoeira, de que, pelo simples fato dessa atividade estar inserida na academia, uma instituição que promove os saberes, o tema capoeira pode ser estudado em maior profundidade e consequentemente adquirir novos contornos. Existe, no entanto, a preocupação da capoeira não ser "engessada" pelo formalismo do ensino universitário. Por estar inserida, na sua maioria, em cursos de graduação em Educação Física, a inquietação se estende aos programas, à metodologia e à redundância dos aspectos fisiológicos.

Fica evidente que mestres e professores acreditam que, na universidade, a capoeira tenderá a evoluir numa outra perspectiva, especialmente a acadêmica. No entanto, têm receios de que possa ser ministrada em uma forma aquém do seu potencial, reduzida aos aspectos técnicos e biológicos, ressaltando que o enfoque deverá contemplar primordialmente a educação pautada na tradição e seus rituais.

A capoeira vem de um segmento bem diferente das demais disciplinas curriculares dos cursos de Educação Física e, por essa razão, é indispensável que ela mantenha suas características fundamentais, absolutamente essenciais à preservação de sua integridade, evitando, assim, que seja de alguma forma contaminada pelo "cientificismo", tornando-se desse modo uma matéria árida. 
Entendemos ser de competência da universidade incentivar pesquisas de toda ordem e abraçar a capoeira como uma manifestação cultural bem difundida nas camadas populares, propiciando oportunidades diversas de estudos aprofundados, com a finalidade de resguardar e resgatar essa inusitada manifestação que representa a história e a identidade do povo brasileiro.

Quantos aos aspectos educativos e sociais, encontramos fortes argumentos que justificam a entrada e a permanência da capoeira no meio universitário, especialmente como disciplina de formação profissional. Foram devidamente enaltecidos os aspectos pedagógicos, filosóficos, educacionais, culturais, históricos, sociais, integradores, prazerosos, artísticos, lúdicos, marciais, folclóricos e tradicionais. Verificamos, ainda, uma orientação e uma valorização dos atributos de corporeidade, habilidade motora, resistência cultural, musicalidade, espírito de grupo e liberdade de expressão.

A rigor, cremos, também, que a capoeira, fazendo parte do ambiente acadêmico, tende a descobrir novos horizontes, a ser mais valorizada. Sabemos que a universidade é uma instituição de prestígio, de difusão do conhecimento e que a capoeira, uma atividade popular, poderá ser oportunizada em uma amplitude maior, passando pelo crivo das pesquisas e das novas descobertas.

Percebemos, no entanto, uma enorme preocupação de que a capoeira dentro da universidade não venha a perder sua essência, "evoluindo" unicamente para o academicismo. É importante que se incorporem aos procedimentos didático-pedagógicos, conteúdos e formas próprias que representem a autenticidade e a originalidade no ensino da capoeira.

\section{CAPOEIRA NA UFBA}

A capoeira, na Universidade Federal da Bahia, iniciou-se de maneira formal com o Departamento de Educação Física ligado à Superintendência Estudantil, em 1978, por força do Decreto-Lei $n^{\circ}$ 69.450, de novembro de 1971, que regulamenta o artigo 22, da Lei $n^{\circ}$ 4.024, de 20 de dezembro de 1961, e a alínea " $e$ ", do artigo 40, da Lei no 5.540, de 28 de novembro de 1968. Tais dispositivos tornaram a prática da educação física obrigatória em todos os níveis e graus de escolaridade.

Como não podia deixar de acontecer, a capoeira passou a fazer parte do elenco das disciplinas oferecidas na Prática Desportiva, a partir do segundo semestre de 1978. Logo de início, foram abertas quatro turmas, sendo duas para o sexo masculino e duas para o sexo feminino, todas elas voltadas para a iniciação, perfazendo um total de cento e sessenta vagas, que foram preenchidas e muito bem aceitas pelos acadêmicos.

Na prática, a distinção dos sexos nunca funcionou e, para um melhor andamento do curso, as turmas desde o início foram divididas em níveis: nível 1 - alunos iniciantes, ou seja, aqueles que nada sabiam de capoeira, principalmente referente aos seus movimentos; Nível 2 - alunos mais adiantados, aqueles que tinham alguma noção ou mesmo já eram capoeiristas. 
O método usado foi o da Capoeira Regional e o principal objetivo era proporcionar, ao aluno iniciante no referido curso e sem nenhum conhecimento da atividade, a habilidade de sair jogando capoeira na roda. Todo o aprendizado acontecendo de forma integrada, com a transmissão do conhecimento não se dando somente pelo aspecto técnico, pois o ensino dos golpes e sequências é acompanhado dos elementos que envolvem a sua cultura, história e evolução.

A disciplina capoeira ministrada na Prática Desportiva é oferecida para todos os cursos da universidade, e tem no seu conteúdo a fundamentação básica da capoeira, enfocando aspectos teóricos e práticos, distribuídos em trinta horas semestrais, sendo equivalente a um crédito. Os alunos são obrigados a frequentar $75 \%$ das aulas para lograrem aprovação. Durante o curso, as primeiras aulas têm como objetivo melhorar o condicionamento físico e a habilidade motora para, em seguida, serem ministradas aulas sequenciais para o aprendizado do movimento fundamental, a ginga, e dos movimentos básicos: aú, cocorinha, negativa e rolê. Dando continuidade, todo o processo é respaldado na Sequência de Ensino de Mestre Bimba, e essa etapa tem uma duração de, aproximadamente, quatorze horas/ aula. Nesse ponto, os alunos já dominam a sequência e detêm um conhecimento teórico da historicidade e dos conceitos básicos da roda, estando inteiramente aptos a jogarem pela primeira vez na roda de capoeira. Isso reflete, integralmente, a filosofia do Mestre Bimba.

Faz parte desse momento a Festa de Batizado, que se caracteriza por uma etapa vencida. Abreu diz que a noção do batizado afirma uma condição essencial para a continuidade do aprendizado, representando um símbolo de uma nova etapa (1995, p. 57). É um dia especial que marca um forte vínculo com a capoeiragem, quando se ganha na roda, nome de guerra e padrinho. E conta com a participação de capoeiristas convidados e renomados mestres, sendo proferidas palestras sobre temas específicos e feita a saudação dos mestres presentes aos novos capoeiristas. O aluno participa do batizado jogando pela primeira vez na roda e, inevitavelmente, ganha um apelido característico (nome de guerra).

As aulas subsequentes têm como conteúdo o aprendizado de novos golpes, como rasteira, tesoura de frente, tesoura de costa, vingativa, escorão e o aprimoramento do jogo. Jogar capoeira na roda é algo extremamente excitante, que proporciona uma motivação toda peculiar, tendo o educando a oportunidade de vivenciar confrontos ricos, interagindo com outros colegas, expressando toda sua evolução no aprendizado, criatividade, expressão corporal e plasticidade.

A roda de capoeira é um rito que foi preservado pelo Mestre Bimba como uma das mais ricas ocasiões de aprendizado. Para Costa, a roda tem uma dimensão profunda que mantém o espírito harmônico com o cosmo maior, movimentando grande quantidade de energia devido à soma de todas as energias presentes (1993, p. 114). Complementando o curso, acontecem aulas teóricas, discussões, debates e seminários versando sobre assuntos inerentes à capoeira.

Inicialmente, as matrículas não selecionavam os alunos pelo nível de aprendizagem (nível 1 - alunos iniciantes, nível 2 - alunos que já tinham experiência na capoeira). Para 
uma melhor organização e rendimento no aprendizado, houve a necessidade de separar as turmas de acordo com o nível de conhecimento e, consequentemente, foram alterados os conteúdos.

Para os alunos do nível 2, além dos assuntos já citados, as aulas práticas enfocaram o aprimoramento da sequência de Mestre Bimba, cintura desprezada, treinamento de golpes separados, execução de exercícios acrobáticos e exercícios específicos para desenvolver as qualidades físicas como flexibilidade, força, resistência, equilíbrio, agilidade e velocidade. Ao educando, o treinamento na roda serve como aprimoramento do jogo, vivência de novos ritmos e toques e participação ativa na orquestra e coro.

Com a implantação do Curso de Licenciatura em Educação Física, em 1988, a capoeira ganha mais um incentivo e passa a integrar o currículo em dois momentos distintos: no primeiro, a Capoeira I como disciplina obrigatória, com carga horária de 60 horas e crédito três, tendo como pré-requisito a disciplina Dimensão Estética da Educação. O programa versa sobre os seguintes assuntos: história, origem, significado da capoeira, fundamentos básicos, jogo, quedas, golpes traumatizantes e desequilibrantes, sequência de ensino de Mestre Bimba, seminários em aulas teóricas e práticas.

A Capoeira II é uma disciplina de aprofundamento de conhecimentos, de caráter optativo, com uma carga horária de 75 horas e crédito três e tem como pré-requisito Capoeira.

O programa consta dos seguintes itens: seminário e apresentações de trabalhos monográficos organizados pelos próprios alunos e ainda atividades extramuros, que contemplam visitas às academias tradicionais e modernas, com a finalidade de conviver mais diretamente com os segmentos da capoeira. Nesta oportunidade, os alunos entrevistam mestres e capoeiristas e participam ativamente das rodas.

Informalmente, a prática da capoeira é mais antiga na Universidade Federal da Bahia, pois surgiu, de maneira espontânea, através dos diretórios acadêmicos, associações atléticas ou mesmo por iniciativa de acadêmicos. Podemos destacar algumas unidades da UFBA que estabeleceram esse contato com a capoeira: Escola de Medicina Veterinária, Faculdade de Medicina, Escola Politécnica, Faculdade de Geociências e Escola de Dança, dentre outras.

A Escola de Medicina Veterinária chegou a manter um grupo folclórico no período de 1970 a 1973. Esse grupo foi formado pela iniciativa do então acadêmico Luciano José Costa Figueiredo (Galo), aluno de Mestre Bimba que gozava de um ótimo conceito na academia. Constituído basicamente de alunos de veterinária, chegou a participar de muitos eventos na capital e no interior e em outras cidades brasileiras.

Outras iniciativas na UFBA merecem referência: o trabalho desenvolvido pelo Mestre Luiz Medicina, na Faculdade de Medicina, e os cursos de extensão oferecidos na Escola de Dança.

\footnotetext{
${ }^{1}$ Comunicação Pessoal, em 1997.

${ }^{2}$ Guaiamum: crustáceo decápode, braquiúro, gecarcinídeo (Cardisoma guanhumi), de coloração azul, cuja pinça maior pode atingir até $30 \mathrm{~cm}$ e cuja carapaça mede até $11 \mathrm{~cm}$. Vive em lugares lamacentos à beira-mar, escondido em tocas
} 


\section{MESTRE XARÉU}

que ele mesmo cava, em profundidades de até quatro metros. Novo Dicionário Aurélio, Versão 5.0 Edição revisada e atualizada Dicionário eletrônico, Positivo.

${ }^{3}$ Ibid Nagôs, povo de língua iorubana que vive a SE da República do Benin.

${ }^{4}$ Instituto Porto Alegre.

${ }^{5}$ Comunicação pessoal, em 1997.

${ }^{6}$ Escola Superior de Educação Física.

${ }^{7}$ Universidade de São Paulo.

${ }^{8}$ Centro de Práticas Esportivas da Universidade de São Paulo.

${ }^{9}$ Comunicação pessoal, em 2005. 